\title{
Bottle rack: a ausência da Coca-Cola nas obras de Marcel Duchamp
}

\section{Bottle rack: the absence of Coca-Cola bottles in Marcel Duchamp's artwork}

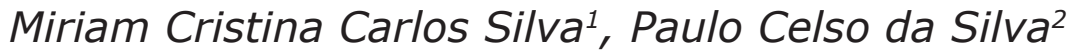

Pós-doutorado em Comunicação Social pela Pontifícia Universidade Católica do Rio Grande do Sul em 2012. Professora titular do mestrado em Comunicação e Cultura da Universidade de Sorocaba, na linha de pesquisa Análise de Processos e Produtos Midiáticos. Lidera o Grupo de Pesquisa em Narrativas Midiáticas (Nami) da Universidade de Sorocaba. E-mail: miriamcriscarlos@gmail.com. com apoio da Fapesp sobre a cidade do conhecimento. Em 2012 desenvolveu um pós-doutoramento na UERJ analisando a produção intelectual do Dr. Milton Santos e a sua aplicação/relação com a Comunicação. Atualmente é professor titular da Universidade de Sorocaba, professor do Programa de Mestrado em Comunicação e Cultura, e suas atividades estão inseridas na linha de pesquisa Mídias e Práticas Socioculturais. E-mail: paulo.silva@prof.uniso.br. 


\section{Resumo}

Palavras-chave

Bottle rack, Coca-Cola, Marcel Duchamp.

\section{Abstract}

This article is the result of a research started in 2015, which involves artistic and media reappropriation of the Coca-Cola brand, as well as the expansion of its symbolic charges. In this particular case, we brought up the Bottle rack, by Marcel Duchamp. To enrich the analysis, we use as reference authors like Paz, Cabanne, Fabbrini, Cage, among others, and we came up with an experiment entitled Coca-Cola's bottle rack. The idea is to perceive an object and its own denial, whilst in dialogue with the viewer, and fulfil this piece of art with his perception and repertoire, as those are formed (or not) in mass societies, cultural industry or the society of spectacle.

\section{Keywords}

Bottle rack, Coca-Cola, Marcel Duchamp. 


\section{Os ready-mades: contextos na arte e na comunicação}

Para Duchamp, o primeiro ready-made foi God (1917), criado pela baronesa Elsa von Freytag-Loringhoven e Morton Livingston Schamberg (PARCERISAS, 2009, p. 114). Do registro fotográfico feito por Morton Livingston Schamberg, sobraram sete fotos, sendo quatro da obra God e três de panorâmicas de Nova Iorque. A Figura 1 reproduz uma das quatro fotografias. Duchamp observava com a mesma irreverência do título da obra que "As únicas obras de arte da América são seu encanamento e suas pontes ${ }^{3 \prime \prime}$ (THE METROPOLITAN MUSEUM OF ART, 2015, s/p).

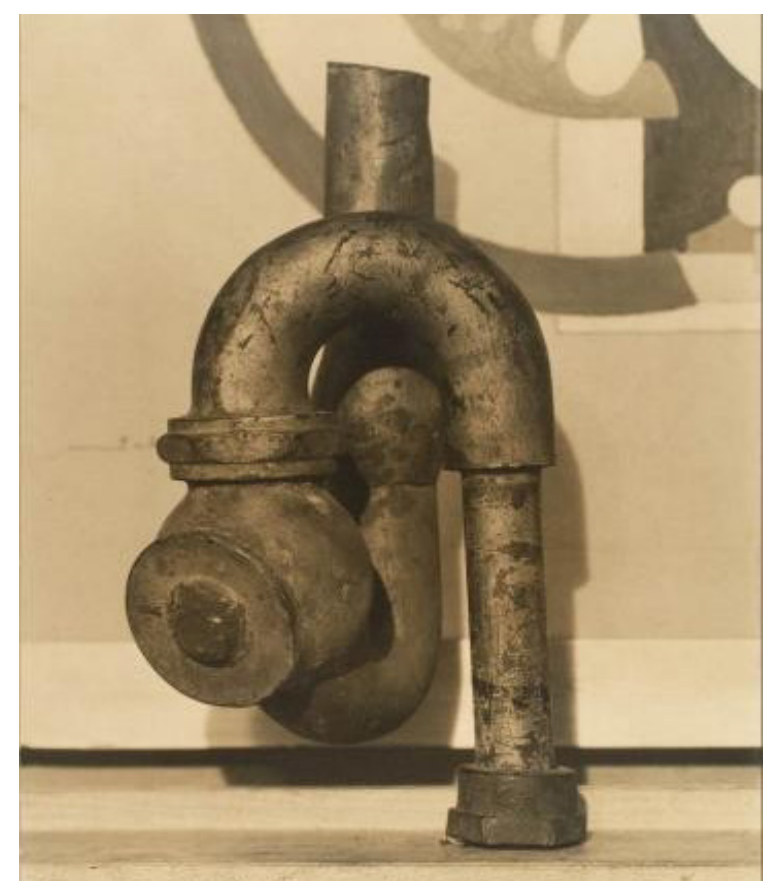

Figura 1: God (1917), de Morton Schamberg e Elsa von Freytag-Loringhoven Fonte: The Metropolitan Museum of Art (2015)

Ao todo, foram 21 ready-mades produzidos por Duchamp com a proposta de provocar nas pessoas outras sensações e consciências estéticas, utilizando, para tanto, outro tipo de arte contemporânea e conceitual, que necessitava não apenas da visão, mas de todos os sentidos e, ainda, acrescentamos a mente como uma espécie de sexto sentido para refletir sobre os objetos, participando, nesse movimento 
concreto-abstrato, da própria reconstrução social do produto indicado pela obra. 0 primeiro ready-made de Duchamp foi Bicycle wheel (Figura 2), em 1915, e pode-se ter uma ideia do que o artista imaginava, já que conforme Stafford (2008) cinco aspectos marcam esses objetos: "ocioso prazer visual, efeito cômico, justaposição entre movimento e êxtase, evocação de lembranças caseiras e históricas".

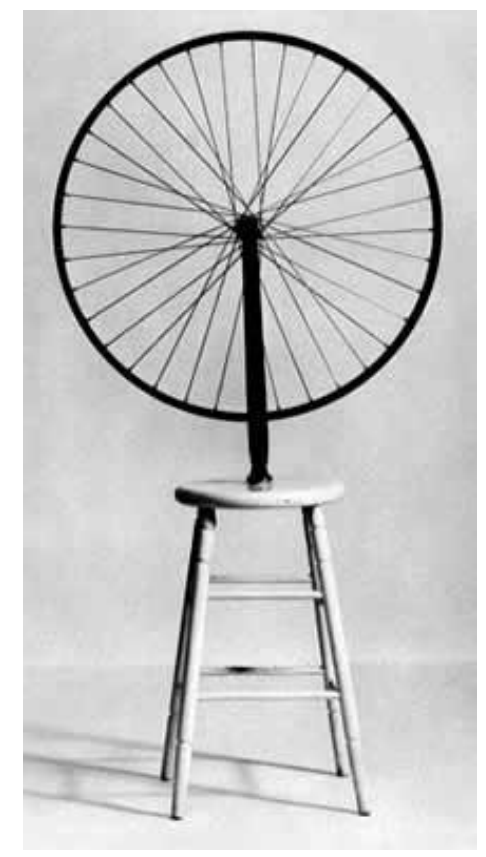

Figura 2: Bicycle wheel (1913), por Marcel Duchamp Fonte: Site Educação Pública (s/d) .

De todos os ready-mades produzidos e sem dúvida da importância de todos eles para a sociedade contemporânea, Fountain (1917) talvez tenha sua imagem como a mais conhecida.

A fonte foi um objeto hoje podemos encontrar facilmente nos Estados Unidos, o modelo Mount Urinal - White Porcelain, By Sloan, por exemplo, custa atualmente US\$255.58 (2017) e pode ser adquirido, inclusive pela internet. Dessa maneira, o objeto produzido em escala industrial não trazia nenhuma novidade em sua forma ou utilidade. Entretanto, Duchamp grafa o pseudônimo "R. Mutt 1917" 
e o inscreve como obra de arte na mostra coletiva, organizada pela Society of Independent Artists, a qual ele havia sido escolhido como jurado. Entretanto, os demais jurados não aprovaram a peça, argumentando desde plágio de um produto industrializado até o questionamento estético se aquilo seria arte ou não.

Na Revista Blind Man, um articulista anônimo rebate a decisão dos jurados afirmando: "Se o Sr. Mutt com suas próprias mãos fez a fonte ou não, não tem nenhuma importância. Ele escolheu. Ele tomou um artigo comum da vida, colocou-o de forma que seu significado útil desapareceu" (Blind Man, 1917, p. 5-6). O Artista anônimo era o próprio Duchamp, também editor da revista.

A primeira Fountain, a que aparece nas páginas da Revista The Blind Man, poucos conheceram. Com o resultado da comissão julgadora, o objeto foi levado para a 291, galeria de propriedade de Alfred Stieglitz, que a fotografou. "Este é o único registro visual remanescente da Fountain original" (FUNCKE, 2014, p. 277). Dessa forma, Duchamp garantiu que a representação midiática passasse a ter um apelo histórico pois a peça original desapareceu (Figura 3), ficando também a narrativa nas páginas da Revista The Blind Man (Figura 4).

Consciente do papel que representava os ready-mades para a arte, pois várias cópias do Fountain viriam depois desse acontecimento, Duchamp nos faz refletir e questionar os valores estéticos, econômicos, de singularidade da arte e também formais, pois a foto da obra tinha o mesmo status de originalidade, mesmo sendo cópia e/ou simulacro.

No entanto, Fabbrini (2010, p. 16) nos alerta também que:

Nos últimos anos tem sido tão frequente a apropriação pela crítica de arte dos ready-made de Duchamp na tentativa de interpretar a arte pós-vanguardista que é possível até mesmo indagar se o próprio artista não acabou convertido, malgrado ele próprio, em ready-made. É preciso lembrar, contudo, que em um ready-made, como dizia Gérard Genette, "a obra não é o objeto exposto, mas o fato de se o expor". (GENETTE, 1994 , p. 155) e que a repetição do mesmo ato - contrariando o lema de Duchamp: "Não repetir apesar do bis" - acarretou a degradação imediata do estranhamento, sua recaída no gosto e o deslocamento de seu sentido originário, de modo que esse ato não causa mais polêmica no público, nem produz a desestabilização das categorias da crítica. 
Acreditamos que Duchamp traga a resposta para a indagação de Fabbrini quanto ao fato de ele próprio ser um ready-made. No texto Apropos of Readymades, afirma que: "Eu percebi logo o perigo de repetir indiscriminadamente essa forma de expressão e decidi limitar a produção de 'ready-mades' a um pequeno número anual" (TAYLOR, 1966, p. 46). Dessa forma, Duchamp indica ter o completo domínio do processo a que se dedica com as obras e da maneira como elas podem ser referenciadas pelas mídias. Tanto é que ele próprio manteve uma forma de registro que no limite é uma nova obra, ou seja, seus registros foram feitos, por exemplo, por Man Ray e Alfred Stieglitz, ambos artistas reconhecidos.

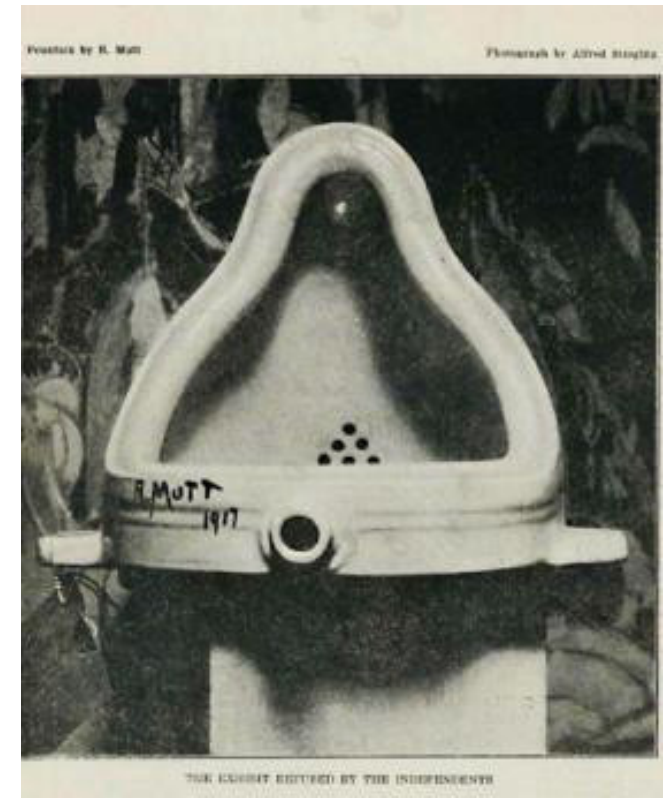

Figura 3: Fountain (1917), por R Mutt.

Fonte: The Blind Man n. 4 (1917).

Em 1949, durante o simpósio The Western Round Table on Modern Art, que discutia as estéticas e possibilidades artísticas inauguradas com o modernismo, Marcel Duchamp afirmava a impossibilidade da tradução da emoção estética em palavras, na mesa de debates "Arte para Todos, Arte para Poucos", da qual participava com Gregory Bateson, Frank Lloyd Wright e com George Boas como moderador. Explicava assim sua visão para o tema proposto: 
Por "Arte para Todos, Arte para Poucos", nós queremos dizer que todo mundo é bem-vindo para olhar livremente para obras de arte e tentar escutar o que eu chamo de um eco estético. Também significa que a arte não pode ser entendida através do intelecto, mas é sentida através da emoção que apresenta alguma analogia com a fé religiosa ou com a atração sexual - um eco estético. Isto é tudo que posso dizer para dar uma equivalência objetiva ao modo que uma emoção estética se manifesta. O ponto importante aqui é diferenciar gosto do eco estético. O gosto passa uma sensação sensível, não uma emoção estética. $O$ gosto pressupõe um observador dominante que determina o que gosta ou não gosta, e traduz isso em "belo" e "feio" quando sensivelmente satisfeito ou insatisfeito. Bem diferente, a "vítima" de um eco estético está na posição comparável à de alguém apaixonado ou de um crente, que deixa de lado as exigências do seu ego e, desamparado, submete-se a uma prazerosa e misteriosa força. Enquanto exercendo seu gosto, ele assume uma atitude de comando; quando tocado por uma revelação estética, o mesmo homem entra num estado de espírito quase de êxtase, torna-se humilde e receptivo (DUCHAMP, 2015).

\section{THE BLIND MAN \\ The Richard Mutt Case}

They say any artist paying Now Mr. Mutt's fountain is not $\begin{array}{ll}\text { six dollars may exhibit. } & \text { immoral, that is absurd, no more than } \\ \text { a bath fub is immoral. It is a fixture that }\end{array}$ Mr. Richard Mutt sent in a you see every day in phumbers' show windows. fountain. Without discussion Whether Mr. Mutt with his own hands this article disappeared and made the fountain or not has no importance. never was exhibited. $\quad$ of life, placed it so that its useful significance What were the grounds for refusing disappeared under the new title and point of Mr. Muti's fountain:-

1. Some contended it was immoral, vulgar.

2. Others, it was plagiarism, a plain piece of plumbing.

As for plumbing, that is absurd. The only works of art America has given are her plumbing and her bridges.

"Buddha of the Bathroom"

I suppose monkeys hated to lose their ing thing about our human institution is tail. Necessary, useful and an ornament, that although a man marry he can never monkey imagination could not stretch to a be only a husband. Besides being a moneytailless eristence (and frankly, do you see making device and the one man that one the biological beauty of our loss of them?), Woman can sleep with in legal purity withyet now that we are used to it, we get on out sin he may even be as well some other pretty well without them. But evolution woman's very personification of her ab1s not pleasing to the monkey race; "there stract idea. Sin, while to his employees he
is a death in everv change" and we monkeys is nothing but their "Boss," to his child ren do not love death as we should. We are only their "Father," and to himself cerlike those philosophers whom Dante placed tainly something more complex. in his Inferno with their heads set the But with objects and ideas it is different. wrong way on their shoulders. We walk Recently we have had a chance to observe forward looking backward, each with more their meticulous monogomy. of his predecessors' personality than his When the jurors of The Society of Inown. Our eyes are not ours. The ideas that our ancestors have joined the bit of sculpture called the Fountain Dissociation des Idees, Remy de Gour- was in by Richard Mutt, because the object mont, quietly analycic, shows how sacred is minds with a cersain natura furcio atavistic the marriage of ideas. At least one charm- secretive sort. Yet to any "innocent" eye

Figura 4: The Blind Man, p. 5.

Fonte: The Blind Man n. 2 (1917). 
A intervenção de Gregory Bateson segue a proposta de Duchamp sobre o eco estético, contudo, suas referências estão em sociedades como Nova Guiné e Índia Holandesa (Indonésia), as quais considera menos confusas que as sociedades ocidentais, inclusive a arte nesses territórios não está dissociada da vivência cotidiana, "Eles não vivem em uma cultura em que a maioria das coisas é misteriosa ou escondida nas enciclopédias, ou em fontes ainda mais obscuras. [...] São afirmações, se preferir, mágicas ou estéticas do sentido que o mundo faz para eles" (DUCHAMP, 2015). Para o Antropólogo, a rápida mudança da cultura e dos padrões estéticos (ecos) indica que se busca (ainda) um mundo mais linear e constante. O crítico literário Kenneth Burke, em sua intervenção, encaminha a reflexão para o problema da comunicação nas sociedades ultraespecializadas. Afirma ele:

Eu acredito que o verdadeiro problema aqui - sem haver uma completa solução para ele - é que há na sociedade uma cultura da especialização; e uma cultura especializada tem essa característica específica no que concerne os problemas de comunicação. Ou seja, um engenheiro de pontes que sabe tudo sobre como se constrói pontes, e ninguém mais que usa a ponte sabe como ela foi construída. Apesar disso, ele se comunicou caso tenha feito uma ponte que as pessoas consigam atravessar. Isto é, dentre todas as profissões, há comunicação entre especialistas das ciências, devido a concretização de um ato em especial. No campo da arte existe acima de tudo o problema da comunicação. Mas o artista, também um especialista, tem um conhecimento especial; e na medida que o público não consegue entender sua linguagem especial, eu acho que aí temos um problema adicional que não é possível resolver completamente na nossa sociedade (DUCHAMP, 2015).

Mantendo suas posições teórico-práticas, Duchamp declara a independência da obra de arte com relação ao artista, inclusive insistindo na primazia da obra:

Nós não enfatizamos o suficiente que a obra de arte é independente do artista. A obra de arte vive por si mesma, e o artista que acaba por fazê-la é como um veículo irresponsável. Nenhum artista em nenhum momento pode dizer: "Sou um gênio. Vou pintar uma obra-prima" (DUCHAMP, 2015 ).

E quando o debate indica que os demais participantes optam mais pelo artista que pela obra, Duchamp será enfático: 
Eu acho que o importante é a introdução da obra como o principal. Deixe que o artista seja secundário. E também o que chamamos de espectador vem depois do que sobrou do século passado, das obras de arte e não dos artistas. Se somos tão orgulhosos para nos considerarmos seres humanos, não deuses... Quero dizer, é tão absurdo colocar o homem antes da obra. Veja, nós damos vida a uma coisa que tem vida, tem uma vida própria enquanto obra-prima (DUCHAMP, 2015).

Gregory Bateson parece concordar com Duchamp, mas não está totalmente convencido: "Sim, talvez exista aí um assunto que devêssemos levar mais em consideração.". Mas Duchamp replica que "Em outras palavras, o artista é apenas a mãe" (DUCHAMP, 2015).

Com relação a essa liberdade da obra de arte em fazer-se ou mostrar-se ao mundo, implica também em liberdade do artista em atualizá-la para si e para os demais e, mais concretamente, em atualizar essa pré-existência, sem o que não teríamos a materialidade da obra.

Sobre esse tema, John Cage, escrevendo acerca de Duchamp nos anos derradeiros da década de 1970, expõe que:

Ele simplesmente achou aquele objeto e the deu seu nome. Que fez ele então? Achou aquele objeto e Ihe deu seu nome. Identificação. Que faremos então? Chamaremos o objeto pelo nome dele ou pelo nome do objeto? Não é uma questão de nomes (CAGE, 2013, p. 70).

Cage ainda dedica outras linhas para o artista e seu método de trabalho e também para o amigo, com o qual esteve aprendendo xadrez e passando semanas de férias nas praias de Cadaqués (Catalunha).

Nesse método, em que o centro não está em nomear, Cage afirma perguntando se "[¿ não $\dot{c}]$ seria 'Duchamp Mallarmé?'" e afirmando pergunta "[¿ é ?] 'Um Duchamp'"' (CAGE, 2013, p. 69-70). ${ }^{5}$ 
O poeta Octavio Paz também aprofundou os estudos sobre as obras de Duchamp e seu papel para a arte contemporânea e para a modernidade, na qual estava incertado, mais do que insertado.

Esse jogo de palavras, por sinal, foi o método que Duchamp utilizou para criar seus trabalhos, inclusive afirma que Raymond Roussel foi uma das grandes influências criativas, pois "senti que, como pintor, era melhor sofrer a influência de um escritor que a de outro pintor. E Roussel me mostrou o caminho." (PAZ, 1977, p. 16). O método consistia em utilizar duas palavras de sonoridades semelhantes e sentidos opostos. Roussel exemplifica no seu texto Como escrevi alguns de meus livros (Comment j'ai écrit certains de mes livres), de 1935, e afirma que explicaria seu método porque ele seria muito útil aos escritores do futuro. Inicialmente, escolhia duas frases: $1^{\circ}$ ) Les lettres du blanc sur les bandes du vieux billard. $2^{\circ}$ ) Les lettres du blanc sur les bandes du vieux pillard. Mesmo o leitor que não domine o idioma francês, percebe a semelhança sonora das palavras, que ele considerava como metagramas, não importando em nada seu sentido lógico. Traduzindo livremente e buscando-se um processo de transcrição sonora das sentenças temos: $1^{\circ}$ ) As letras brancas nos bandos da velha piscina. $2^{\circ}$ ) As letras brancas nos bandos da velha ladrina.

Explica o autor que na primeira frase, a palavra "letras" direcionava para os signos tipográficos, como alguém escrevendo com giz, e bandas indicava fronteiras; na segunda frase, "a palavra letras" indicava "letras", branco indicava "homem branco" e "bandas", como "gangues" (ROUSSEL, 1935). Para Paz o artista francês percebeu esse movimento proposto por Roussel e ampliou o jogo com as palavras para uma combinação "plástica e mental" e, diferente do escritor, acrescentou a metaironia (PAZ, 1977, p. 16). Essa transposição "que consiste em tornar imaginário todo objeto real: a imaginação reduz a realidade à ideia $[\ldots]$ se o mundo é ideia, sua maneira própria de existir não pode ser outra senão a linguagem absoluta" (PAZ, 2012, p. 114). A influência de Roussel é confirmada, ainda, pelo próprio Duchamp, em entrevista de 1966, quando explica que apreciava os jogos de palavras, entretanto, "isso me interessava 
de maneira bastante artificial; eu não escrevia... Ele me deu a ideia de que, eu mesmo poderia tentar alguma coisa naquele sentido, ou ainda, anti-sentido" (CABANNE, 2012, p. 68).

O jogo dos sentidos das palavras ainda viria com a criação da personagem Rrose Sélavy e do nome do quadro da Mona Lisa com bigode e cavanhaque, L.H.O.O.Q., criado na busca de uma experiência nova cuja primeira proposta era trocar a religião: de um nome católico para um judeu. Não encontrando o nome judeu que o agradasse, pensou em mudar o sexo, "pois seria muito mais simples!" e conforme o autor, na década de 1920, "Rrose era um nome estúpido" (CABANNE, 2012, p. 110). O nome saiu de uma assinatura feita em um quadro de Picabia, no qual grafou outra brincadeira: "en 6 qu 'habillarrose Selavy". Já no nome da Mona Lisa de Duchamp, o que interessa é o som da soma das letras, que em francês seria algo como Elle à chaud au cul, que em tradução livre pode ser "Ela tem o rabo quente". Duchamp relembra em várias passagens que "é sempre a ideia de 'diversão' que me levava a fazer as coisas" (CABANNE, 2012, p. 79). Paz conclui que essas experiências linguísticas-plásticas "confirmam sua decisão de romper não somente com a pintura 'retiniana', mas com a concepção tradicional de arte e com o uso vulgar da linguagem (comunicação)" (PAZ, 1977, p. 18).

A "metodologia" do artesão francês, como preferia ser considerado, incluía o acaso, sem contudo perder de vista que "a intenção consistia, acima de tudo, em esquecer a mão, pois, na verdade, mesmo a sua mão não é o acaso" (CABANNE, 2012, p. 78). Não foi diferente com os ready-mades. Em 1915, com Bicycle wheel, o que interessava era a distração, nenhuma ideia ou proposta subjacente estava envolvida. O Suporte de garrafas (Bottle-dryer, Egouttoir ou Porte-bouteilles, ou ainda, Hérisson) datado de 1914, foi adquirido em Paris um ano antes, junto com o garfo e o aro de bicicleta. Diferente dos demais ready-mades, o Suporte de garrafas (Figura 5) demandou mais atenção de Duchamp.

Tendo deixado seu ateliê de Paris, em 1916, enviou uma carta para sua irmã Suzanne informando sobre as duas futuras obras "já acabadas": 
Agora, quando subires as escadas, tu vês a roda de bicicleta e um suporte de garrafas no meu estúdio. Comprei-os como uma escultura já acabada mas eu tenho uma ideia a respeito do suporte de garrafas. Ouve: Aqui em New York comprei alguns objetos de estilo semelhante e chamei-Ihes reaydmade. Tu sabes suficientemente inglês para perceberes o significado de "já acabado" que eu atribuí a esses objetos - assinei-os e coloquei uma inscrição em inglês... Todo esse preâmbulo tem uma razão de ser: vai buscar o suporte de garrafas. Estou a fazer dele um readymade à distância. Na parte de dentro do arco inferior tu irás escrever a inscrição, que te envio no fim, em letra pequena pintada com um pincel e tinta branca prateada e com a mesma letra assinarás Marcel Duchamp (DANIELS apud MINK, 1996, p. 57).

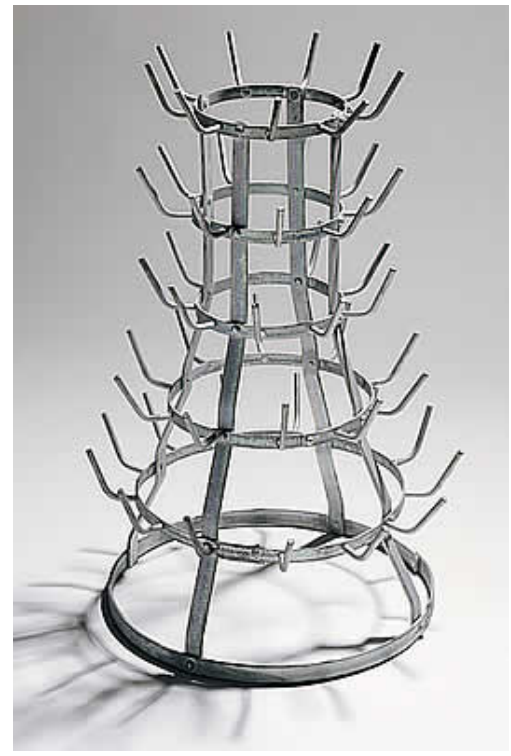

Figura 5: Suporte de Garrafas, 1914/1964

Fonte: Site Educação Pública (s/d) .

A inscrição a que Duchamp se refere nessa carta foi perdida, assim como o suporte, porque sua irmã e cunhada os jogaram fora com outros "lixos" do ateliê. Posteriormente, em 1921, Duchamp de volta a Paris presenteia a irmã com um suporte de garrafas. A primeira aparição pública do Suporte de garrafas será em 1936 em Paris, na galeria Charles Raton, e terá grande destaque entre outras obras surrealistas. 
A descrição da trajetória da obra disponível no livro do Museu de Arte Moderna do Centro Pompidou de Paris, Marcel Duchamp dans les collections $(2001)^{7}$, demonstra a importância que o cenário artístico internacional depositou na obra, assim como a impressão, por vezes negativa do autor, ao analisar o sucesso do ready-made. De 1956 a 1964, a obra participa de exposições em território Europeu e Duchamp afirma a Jean-Marie Drot que "Todos o adoram. Está hoje em todos os livros. É mostrado como uma escultura que as pessoas devem admirar [...] É muito poderoso! este amaldiçoado Herisson (...) inquietante. Tornou-se demasiado 'belo ${ }^{8 \prime \prime}$.

Duchamp assume que o expectador/espectador é parte primordial da criação artística ou artesã, como preferia conceituar. Essa era a maneira como poderia ocorrer a comunicação nessa tríade público-arte-artista, sem que nenhum dos polos estivesse em situação privilegiada com relação aos demais. "Acredito muito no lado médium do artista. O artista faz qualquer coisa, um dia, ele é reconhecido pela intervenção do público [...] Dou tanta importância para aquele que vê quanto àquele que a faz" (CABANNE, 2012, p. 122).

A comunicação proposta por Duchamp rompe com a linguagem artística e com a cotidiana ao propor o novo, o inusitado para uma expressão plástica considerada - por ele - simples, como é o caso do ready-made Suporte de garrafas. O artista leva ao público uma proposta de reflexão que supere o cotidiano imediato, mas que, ao mesmo tempo, não o suplante totalmente, ou seja, para que a comunicação ocorra, Duchamp prevê um reconhecimento, ainda que não duradouro, de sua escolha material agora transformada em readymade. O espectador, ao deparar-se com um suporte de garrafas, reconhece-o como tal em sua função social, como produto industrializado. A seguir, vem o estranhamento da não pertença que esse objeto guarda em si mesmo. A sequência tanto pode ser a reflexão acerca do estatuto artístico - se é ou não 
arte - ou o deleite estético imediato. De todas as formas, o público não está ou fica passivo diante do ready-made. Segundo o próprio Duchamp, o "Suporte de garrafas é poderoso" e evoca no espectador os textos menos retinianos, sejam eles de caráter psicológico, sexuais. Concorre também para o sucesso do ready-made a assinatura de Duchamp. Todavia, é a operação espacial que mais chama atenção nessas obras: "O artista joga a obra para um processo temporal de movimento no espaço do espectador e realça a possibilidade de um ponto de vista específico para cada espectador na construção de uma narrativa particular" (PELED, 2007, p. 1731).

O espaço que a arte ocupa se metamorfoseia com aquele ocupado pelas pessoas e com o das salas dos museus e galerias. Teríamos um espaço-arte, povoado de objetos, rodeados por pessoas-objetos e de pessoas que veem objetos em um recinto que abriga a todos. Um jogo, talvez de xadrez, em que cada peça é um universo de uma peça-personagem da narrativa rumo ao xeque-mate. Ou não.

\section{Suporte de garrafas Coca-Cola - um experimento contemporâneo}

Destacados ready-mades e seu criador, a seguir apresentamos nossa pesquisa-experimento que abrangeu, de forma sistemática, todo ano de 2015, prosseguindo em 2016, na qual partimos da marca Coca-Cola e de alguns de seus desdobramentos culturais (artísticos, midiáticos e cotidianos), desde sua criação em 8 de maio de 1886 nos EUA.

Os trabalhos envolvem um professor de cada linha de pesquisa do Mestrado em Comunicação e Cultura da Universidade de Sorocaba, sendo estas Mídia e Práticas Socioculturais e Análise de Processos e Produtos Midiáticos. Momentos distintos marcam a pesquisa, o que inclui tanto a produção de artigos científicos que abordam questões sociais e econômicas ligadas à marca quanto outros que discutem a apropriação da Coca-Cola na criação artística moderna e contemporânea, investigando narrativas lítero-imagéticas em artistas como Salvador Dalí, Cildo Meireles, Hélio Oiticica, Ai Weiwei entre outros, além da 
produção de uma obra plástica e do registro fotográfico para uma exposição no primeiro semestre de 2016, intitulada "Duchamp wouldn't drink Coca-Cola", como veremos a seguir. Antes, cabe retomar o fato de que, no decorrer das pesquisas, questionamos o que teria levado Duchamp a não utilizar a Coca-Cola como um ready-made ou mesmo como parte de uma obra pictórica ou não, bem como por que ele deveria utilizá-la. Com essas questões, levamos em conta, inclusive, a nacionalidade francesa de Duchamp e um provável não sentido icônico da marca fora dos EUA, além do fato de que o porta-garrafas francês, conhecido no país como Herisson (um porco espinho pequeno) foi projetado e utilizado até hoje para garrafas de vinho. Entretanto, a curiosidade pelo experimento com garrafas de Coca-Cola traz o objeto para a cultura estadunidense, com a qual Duchamp conviveu cotidianamente. Sendo assim como, esteticamente, o Herisson se portaria com garrafas de Coca-Cola? Que diálogos ocorreriam entre esses dois objetos icônicos da sociedade moderna?

Inicialmente, pensamos em adquirir um Herisson francês em sites como eBay, Etsy etc., e a busca tornou-se uma pesquisa produtiva para verificação do alcance do objeto no mercado de antiguidades. Na ilustração abaixo (Figura 6), o preço das peças varia entre $2.223,71$ reais e 338,86 reais, considerando que são de tamanhos e épocas diferentes. Aqui não foi computado o valor do transporte até o Brasil, indicando também que alguns não enviavam para a América do Sul; o preço indicado, apesar de estar em reais, seria cobrado pelas operadoras de cartões de crédito em euros.

No site Rubylane vintage begin here, encontramos por US\$177.00 um modelo pouco usual (Figura 7), por ser metade do outro e que pode ser utilizado também deitado ou apoiado no canto dos cômodos. 


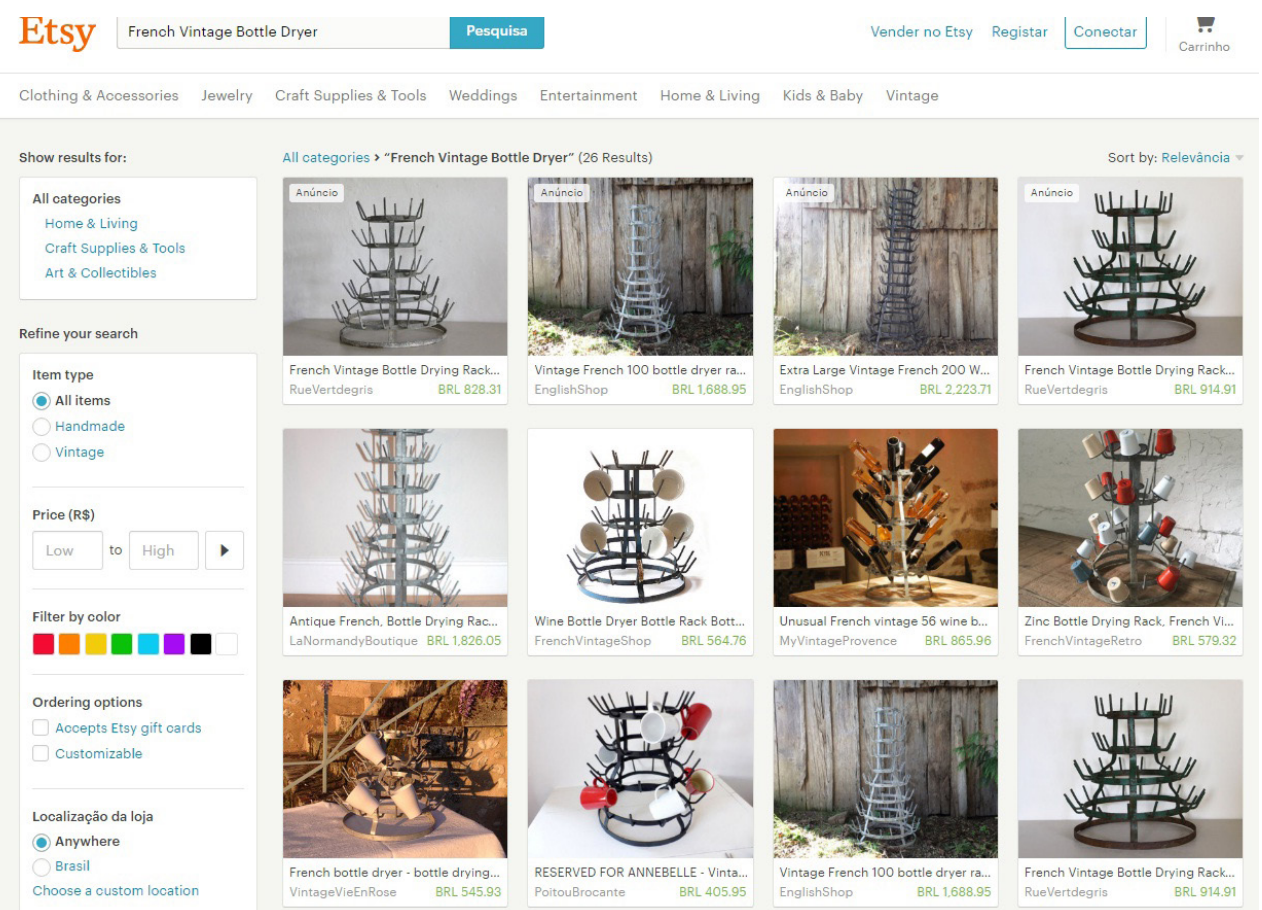

Figura 6: Pesquisa de Herisson francês em sites de venda Fonte: Etsy (s/d ) .

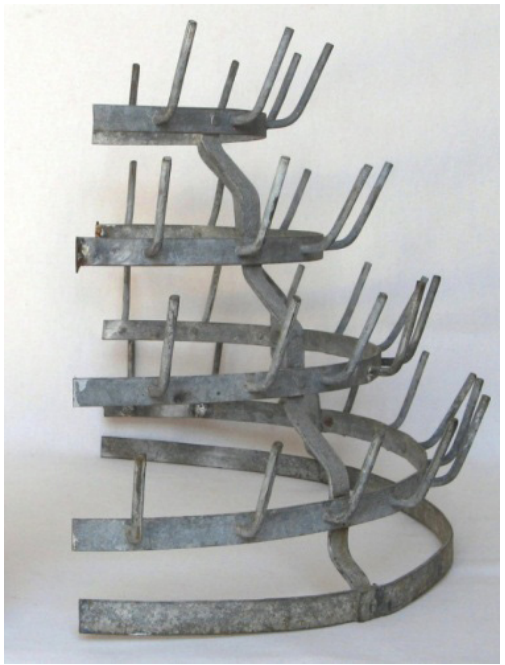

Figura 7: Modelo de Herisson francês

Fonte: Site Ruby Lane (s/d) ${ }^{10}$. 
Em 2002, Phillips de Pury \& Luxembourg colocaram em leilão, e entre catorze ready-mades estava, no lote 4, o Bottle Rack, com preços iniciais entre US\$ 800.000 e US\$1.200,000, contudo, não alcançando tais somas, a obra foi vendida "apenas" por US\$500.000.

Partimos para a construção de uma réplica do Suporte de garrafas, em ferro, medindo $70 \mathrm{~cm}$ de altura e base com diâmetro de $40 \mathrm{~cm}$ (o original desaparecido tinha $59 \mathrm{~cm} \times 37 \mathrm{~cm}$ ) e encaixe para 24 garrafas (Figura 8), processo do qual pudemos participar com o serralheiro. Entretanto, assim como a série produzida em 1964 por Schwarz, nosso Suporte de garrafas Coca-Cola (Coca-Cola's bottle rack) também não é um ready-made, produto já feito ("already made") como definiu Duchamp, pois foi fabricado artesanalmente.

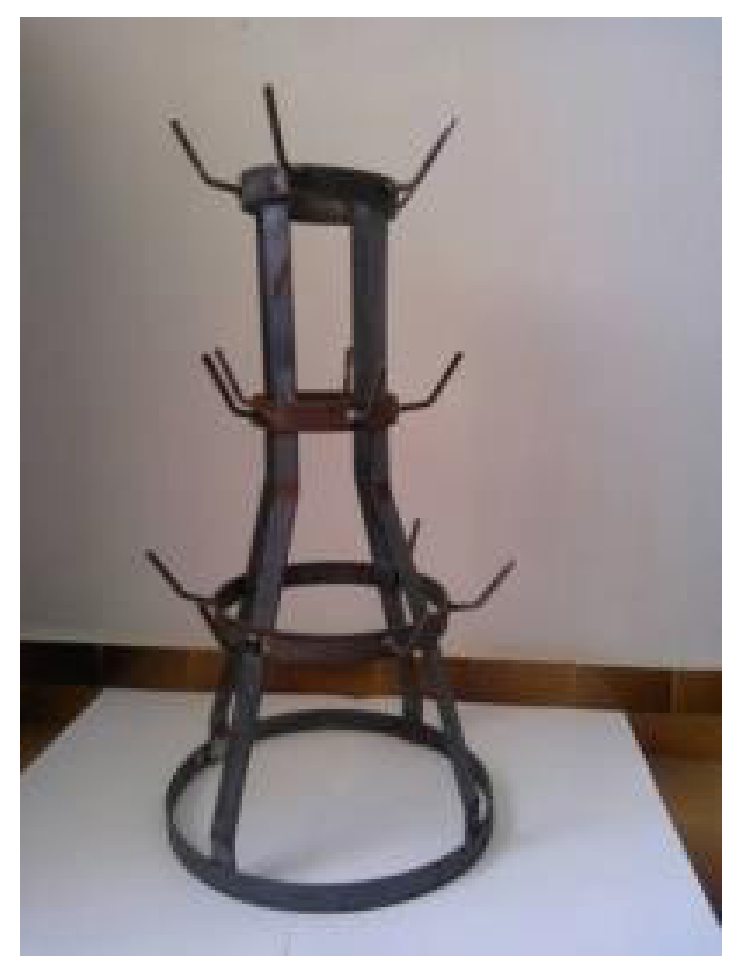

Figura 8: Suporte de garrafas (réplica). Suporte de garrafas Coca-Cola Fonte: Elaboração própria (2015).

Adquirimos garrafas de plástico e de vidro de 200 ml, e algumas foram pintadas de vermelho e, outras, mantidas no original (Figuras 8 e 9). 


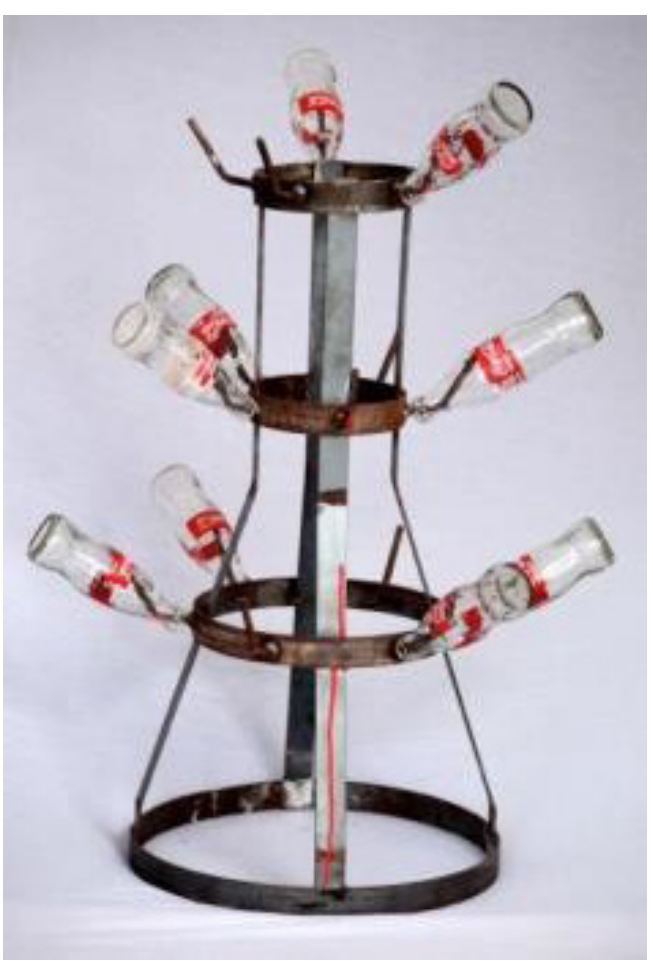

Figura 9: Suporte de garrafas, com garrafas transparentes Fonte: Elaboração própria (2015).

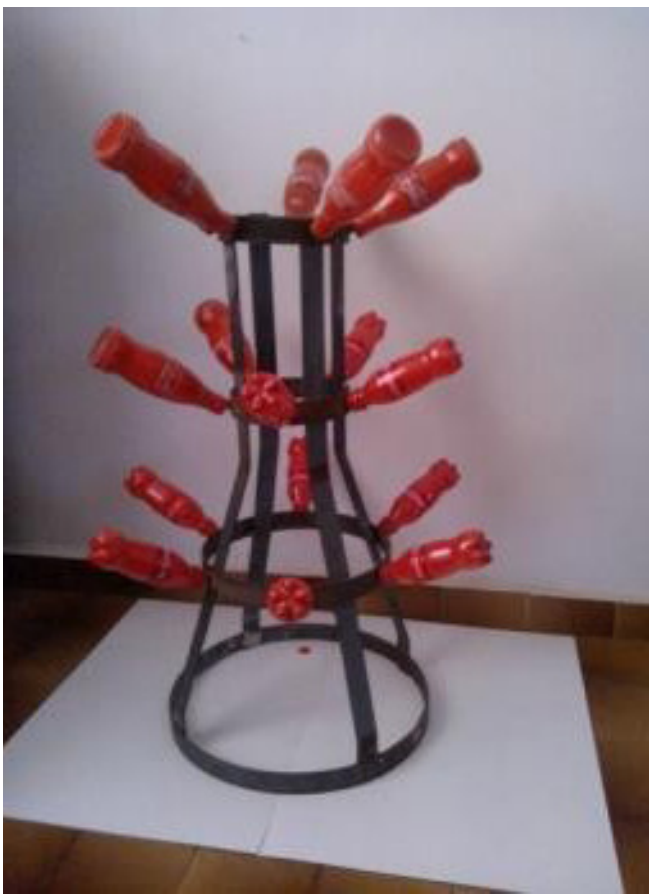

Figura 10: Suporte de garrafas, com garrafas vermelhas Fonte: Elaboração própria (2015). 
Outras composições foram testadas, visando aproximar ao máximo a proposta de uma obra que trouxesse o conceito do Suporte de garrafas como ready-made, ou seja, com as componentes plástica (visual) e literária (intelectual). Na figura abaixo, vemos o experimento da Vênus INS 338 (Figura 10), uma reprodução em gesso da garrafa de Coca-Cola $200 \mathrm{ml}$ e nomeada com o código de um acidulante que, no caso de consumo prolongado, pode causar problemas com o cálcio do corpo humano.

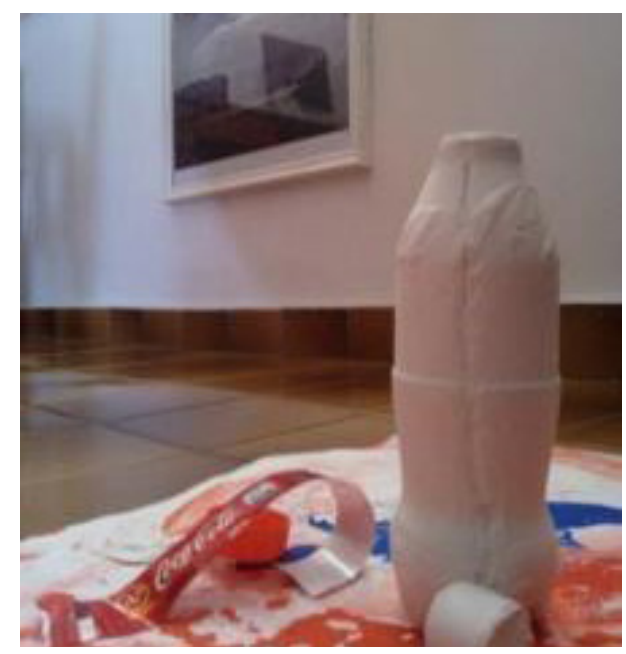

Figura 11: Vênus INS 338 I

Fonte: Elaboração própria (2015).

Nessa perspectiva apostou-se nos detalhes e, como nos pareceu, quanto mais reduzido o número de garrafas, mais equilibrada ficava a composição, principalmente com as garrafas transparentes (Figuras 11, 12 e 13).

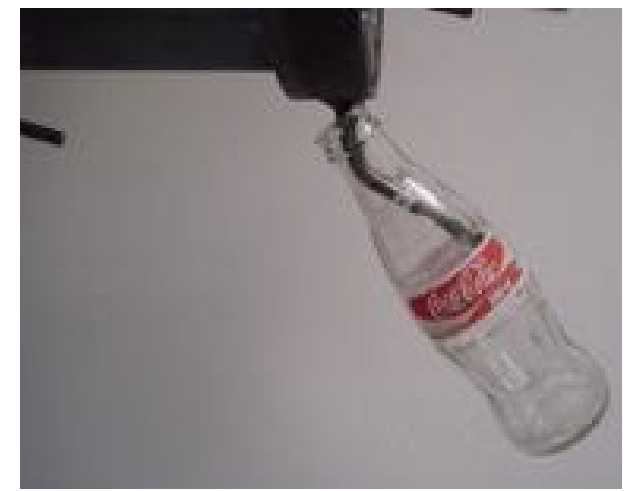

Figura 12: Fragmentos com garrafa

Fonte: Elaboração própria (2015). 


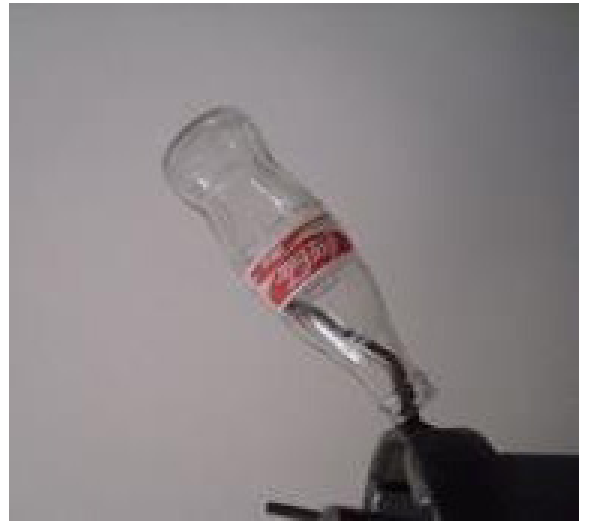

Figura 13: Fragmentos com garrafa

Fonte: Elaboração própria (2015).

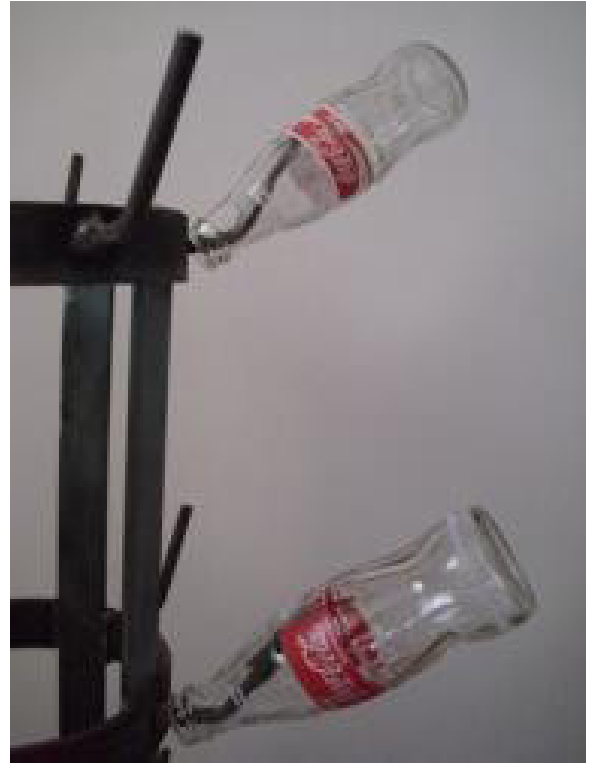

Figura 14: Fragmentos com garrafa

Fonte: Elaboração própria (2015).

Por outro lado, os detalhes utilizando as garrafas como um filtro fotográfico não atingiram o efeito proposto e desviaram para registros além do que estávamos buscando (Figuras 14, 15 e 16) com os ready-mades. 


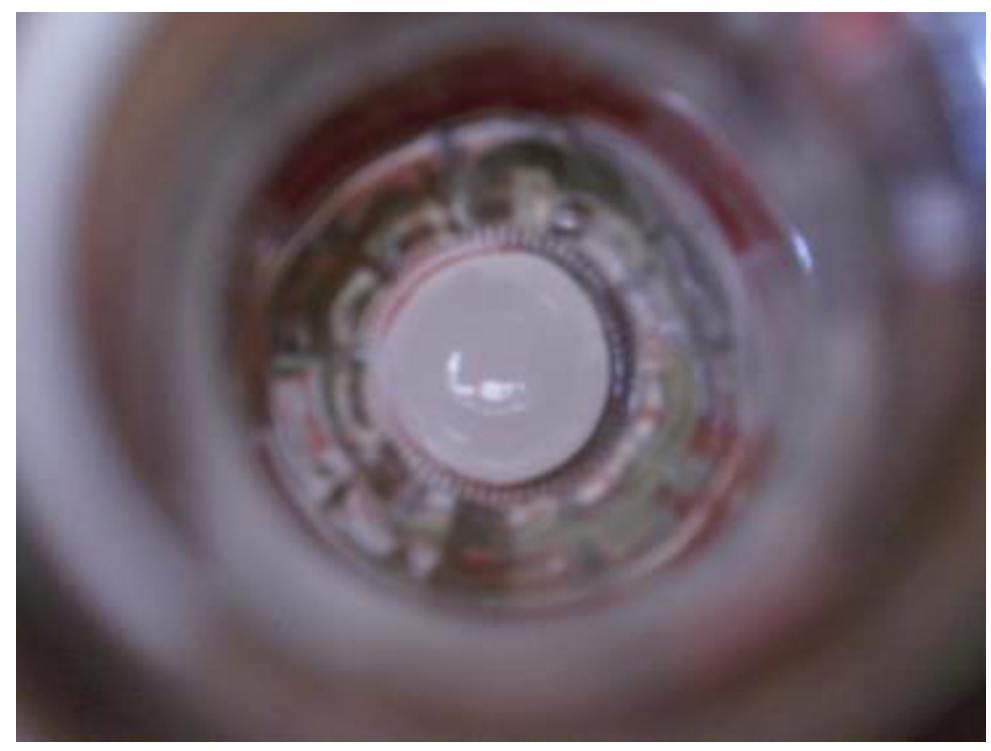

Figura 15: Fragmentos

Fonte: Elaboração própria (2015).

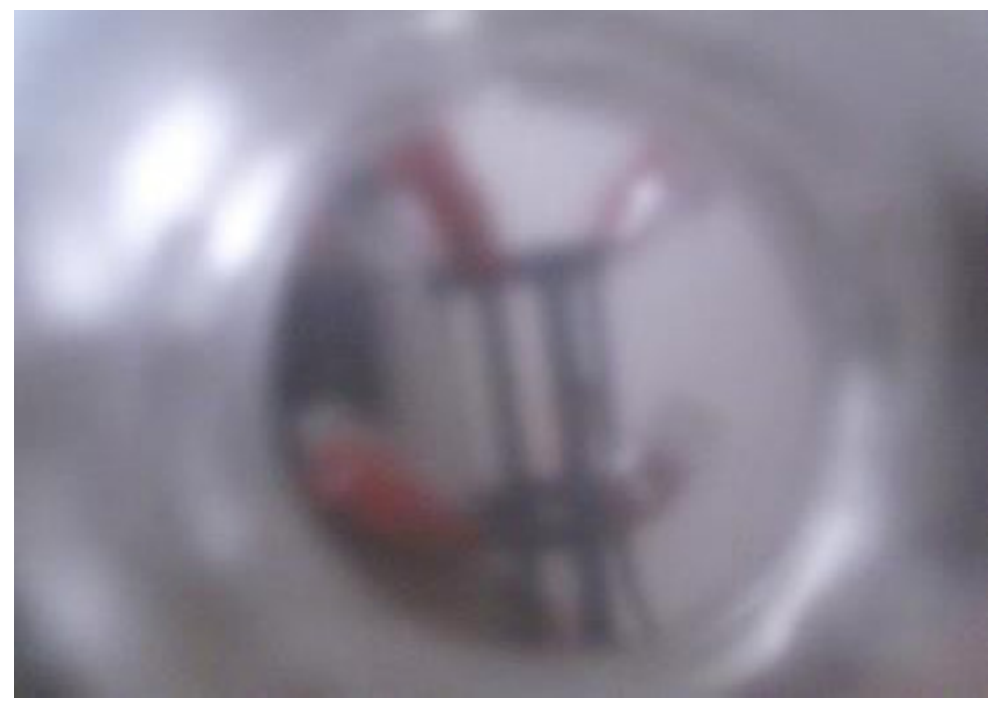

Figura 16: Fragmentos

Fonte: Elaboração própria (2015).

Nesse primeiro momento das reflexões, a Vênus INS 338, aparte de indicar a plasticidade e a literalidade como sugere Duchamp, não tem vinculação direta com o Suporte de garrafas Coca-Cola (Coca-Cola's bottle rack), e pode ser considerada como um adendo ao experimento com o Suporte ou uma criação paralela. 


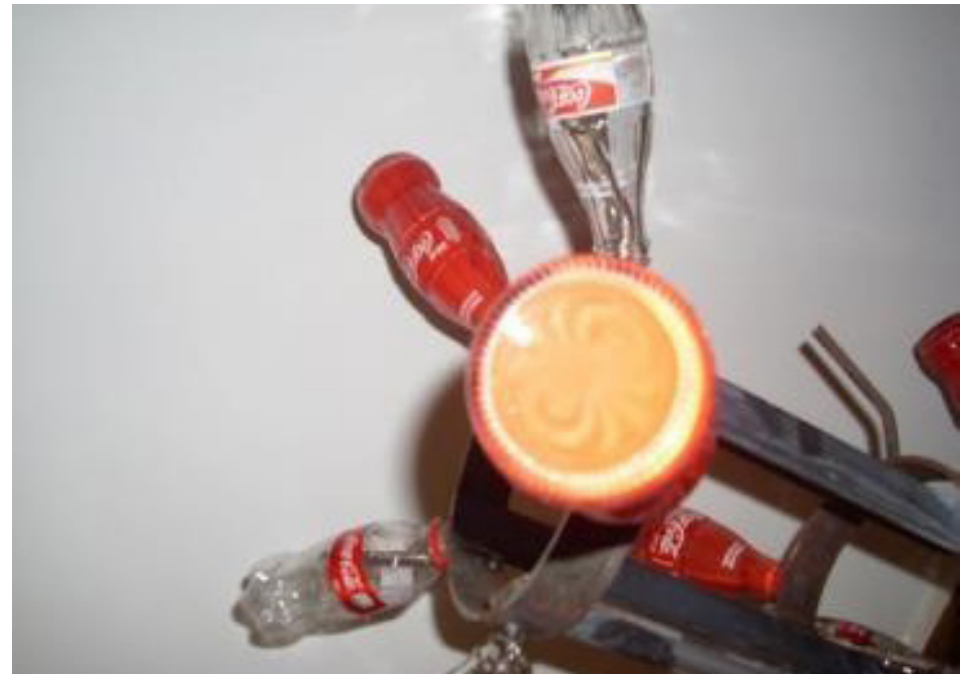

Figura 17: Fragmentos

Fonte: Elaboração própria (2015).

As garrafas pintadas de vermelho e colocadas no Suporte tiraram a plasticidade e a leveza da peça, e ainda não trouxeram a ironia e o estranhamento presentes em Duchamp. Ao contrário, o vermelho da marca Coca-Cola foi reforçado, mas não conseguiu um diálogo nem com as garrafas e nem com o Suporte. Especulamos que o mesmo se daria com as garrafas pintadas de preto, cor do líquido do refrigerante. O que se comprovou conforme vemos abaixo (Figura 17):

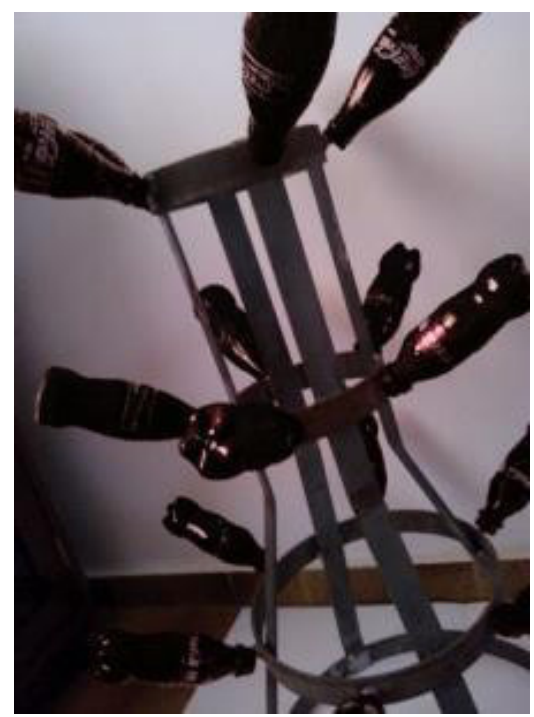

Figura 18: Fragmentos

Fonte: Elaboração própria (2015). 
Isso comprova parte do que Octavio Paz conclui, em seus estudos acerca de Duchamp, ao afirmar que "Os ready-made foram uma crítica tanto do gosto como do objeto" (1977, p. 55). Mais adiante, no mesmo estudo, critica as imitações dos ready-made dispersos e insistentes em museus e galerias por todo o mundo, "degradação do gosto único em aborrecido rito coletivo, do jogo profanador em passiva aceitação, do objeto-dardo em artefato inofensivo" (PAZ, 1977, p. 55).

Paz destaca o fato de que os ready-mades são feitos contra o público e "não são objetos de adoração nem de uso, mas de invenção e criação" (1977, p. 56-57), o que no fundo contraria o próprio Duchamp, que preferia a arte (a palavra e o fato) à criação, pois entendia que o artista "é um homem como qualquer outro, é sua ocupação de fazer certas coisas, mas o homem de negócios também faz certas coisas [...] somos todos artesãos", pois arte significa fazer (CABANNE, 2012, p. 24-25).

Os experimentos com o Suporte de garrafas Coca-Cola (Coca-Cola's bottle rack) nos fazem refletir acerca da linha narrativa que se cria com essa composição e compõe uma constatação empírica básica, a de que Duchamp não usou o Suporte de garrafas nem em 1914 e nem em 1964 com garrafas de Coca-Cola, porque não era um porta-garrafas (Bottle rack), ou seja, falta ao Suporte de garrafas Coca-Cola (Coca-Cola's bottle rack) alcançar a metafísica que o torne irrelevante e invisível, algo talvez impossível quando associado à marca centenária e que sempre investiu na preservação da imagem, a começar pela forma da própria garrafa, logo reconhecida pelo tato graças aos gomos que a identificam. Ao mesmo tempo é a ideia de um objeto de arte e sua própria negação (PAZ, 1977, p. 93-94) ao indicar, nessa dialética, o diálogo com o espectador que "complementa" a obra com sua percepção e seu repertório, seja ou não oriundo da sociedade de massas, da indústria cultural ou da sociedade do espetáculo.

Quando o Suporte de garrafas Coca-Cola (Coca-Cola's bottle rack) quer "reler" o Bottle rack de 1914/1964, a simbiose não acontece e parece que estamos diante de mais de um "parasitismo" das garrafas, que nada retribuem em troca do serviço prestado pelo Suporte. Em determinado momento do experimento, a tinta vermelha de uma garrafa escorre de seu interior e percorre uma das partes verticais 
do Suporte que, imediatamente, a incorpora, criando um risco dramático de tinta vermelha, mas não de sangue. A trama/drama está no fato simples de ser uma tinta de cor vermelha, sem mais simbologias para o espectador. Novamente, o Suporte de garrafas Coca-Cola (Coca-Cola's bottle rack) consegue dialogar consigo mesmo.

\section{Por que Duchamp não usou a Coca-Cola? Ou do por que Duchamp usaria a Coca-Cola?}

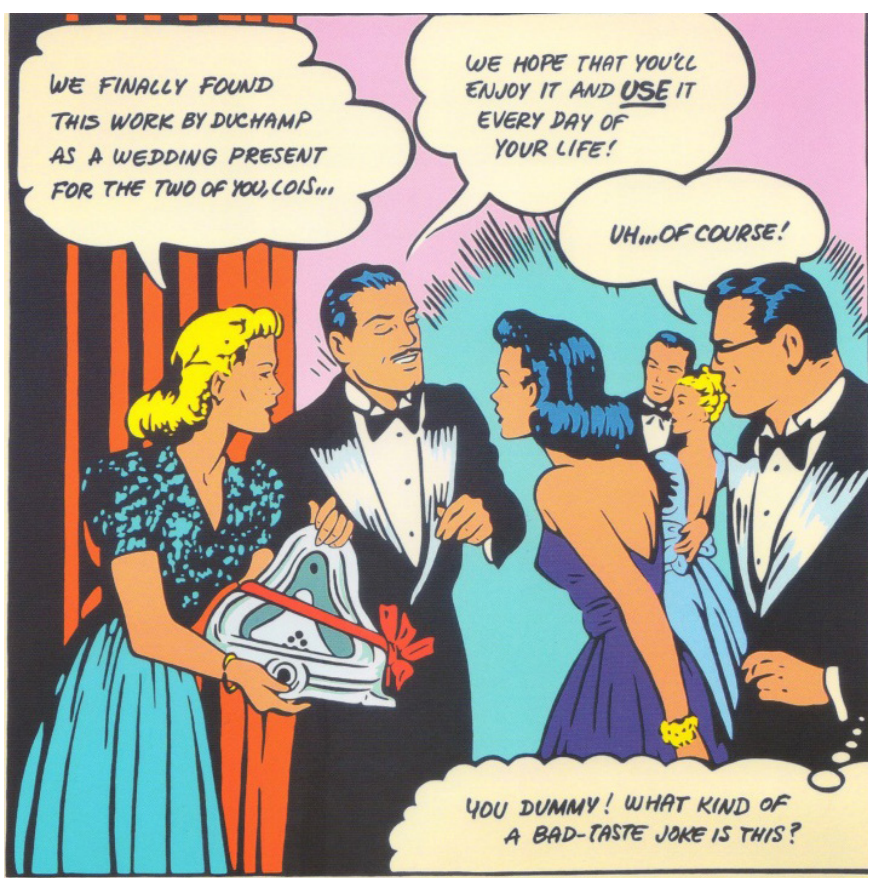

Figura 19: Quadrinho sobre Duchamp. ${ }^{11}$

Fonte: Untitled, 2008. Alvaro Barrios. Nohra Hime Gallery (2008).

As duas questões, deixadas para o final do texto, permitem retomar as propostas de contextualizar Marcel Duchamp e os ready-mades, principalmente o Bottle rack e nosso experimento com o Suporte de garrafas Coca-Cola (Coca-Cola's bottle rack). Assim, reforça-se a ideia de que Duchamp não estava à frente de seu tempo produzindo Pop art, ao contrário o temos, em conjunto com os demais artistas 
de seu meio, exatamente como um representante de seu momento, mas que teve - e aproveitou - as possibilidades de pensar e de construir seu próprio tempo.

Em suas interpretações dos acontecimentos cotidianos, Duchamp pôde captar tanto a banalidade dos produtos em série quanto o debate entre arte superior e inferior (high and low art) e seus respectivos objetos (Figura 18), sendo que suas declarações nos levam a concluir que também considerava esse tema como banal. Sua afirmação "As únicas obras de arte da América são seu encanamento e suas pontes", acerca da obra God (1917), corrobora com sua visão do Zeitgeist (o espírito da época), no caso, o modernismo do século XX e suas repercussões no mundo da arte.

A atenção despertada pelos produtos massificados, culturais ou de uso doméstico de teóricos e artistas - como uma passagem de algo mais transcendente, portador de uma aura (como assim denota Walter Benjamin) ou como um componente metafísico interno, ao gosto de Duchamp - pode ser entendido como uma "garantia" de que a arte tem algo mais a dizer do cotidiano do que supõem os críticos e teóricos. Diferentemente de Kandinski ou de Hélio Oiticica, o artista francês pouco sistematizou sua produção em textos; temos exemplos dele teorizando em 1917, quando escreveu na já citada revista The Blind Man a respeito da não aceitação da Fountain para a exposição, e em 1957, tratando do processo criativo no debate feito com outros intelectuais e no qual se auto intitulou de "mero artista", os demais eram professores universitários.

No texto de 1917, Duchamp questiona a não aceitação da Fountain para participar da exposição, já que era anunciado que "qualquer artista que pagasse seis dólares poderia expor" (THE BLIND MAN N. 2, p. 6), além disso, a Fountain sumiu e nunca foi exposta. Questiona os critérios adotados, das possíveis imoralidades e falta de originalidade da peça. De maneira sucinta, Duchamp registra uma possibilidade teórica para os ready-mades, que ele repetirá em várias ocasiões nos anos posteriores.

Ao ser perguntado por que utilizou latas de sopa Campbell e garrafas de Coca-Cola em suas obras, Andy Warhol responde de maneira muito simples: 
"porque eu bebo. Faz vinte anos que eu almoço isso. Eu faço a mesma coisa sempre" (KATTENBERG, 1996, p. 206).

Duchamp, como homem de seu tempo, criou um espaço para sua arte que apesar de comportar os ready-mades, não comportou o uso e a ressignificação da Coca-Cola para a produção de sua arte. Talvez por não ser um produto do cotidiano de Duchamp. O procedimento do ready-made duchampiano, entretanto, permitiu e vem permitindo a artistas de todo o mundo, em todos os suportes possíveis, múltiplas releituras do signo da Coca-Cola, que, nas mídias, detêm contemporaneamente o uso (e esvaziamento) dos ready-mades, inventa a cada dia novos velhos modos de entreter o público e levá-lo ao consumo do produto e de seu manancial de imaginários.

\section{Referências}

CABANNE, P. Marcel Duchamp: engenheiro do tempo perdido. São Paulo: Perspectiva, 2012.

CAGE, J. De segunda a um ano: novas conferências e escritos de John Cage. Rio de Janeiro: Cobogó, 2013.

DANIELS, D. Duchamp und die anderen: der Modellfall einer künstlerischen Wirkungsgeschichte in der Moderne. Köln: DuMont-Taschenbücher, 1992.

DUCHAMP, M. Ready-made. In: Marcel Duchamp dans les collections. Paris: Centro Georges Pompidou, 2001. Disponível em <https://goo.gl/yc6LuWl>. Acesso em 20 jul. 2016.

Arte para todos, arte para poucos. Revista Usina, [S.I.], n. 21, ago. 2015. Disponível em: <https://goo.gl/S1aUFk>. Acesso em: 20 jul. 2016. 
FABBRINI, R. N. Arte relacional e regime estético: a cultura da atividade dos anos 1990. Revista Científica/FAP, Curitiba, v. 5, p. 11-24, jan./jun., 2010. Disponível em: <https://goo.gl/nvQHMH>. Acesso em: 20 jul. 2016.

FUNCKE, B. Not objects so much as images: a response to Graham Harman's "Greenberg, Duchamp, and the next avant-garde". Speculations: A Journal of Speculative Realism, New York, v. 5, p. 275-285, 2014. Disponível em: <https://goo.gl/QAhEvr>. Acesso em: 20 jul. 2016.

KATTENBERG, P. The value of Warhol. In: KLAMER, A. (Ed.). The value of culture: on the relationship between Economics and Arts. Amsterdam: Amsterdam University Press, 1996. p. 205-213.

MINK, J. Marcel Duchamp 1887-1968: A arte como contra-arte. Lisboa: Taschen, 1996.

PARCERISAS, P. Duchamp en España: las claves ocultas de sus estancias en Cadaqués. Barcelona: Siruela, 2009.

PAZ, O. Marcel Duchamp ou O castelo da Pureza. São Paulo: Perspectiva, 1977. Signos em rotação. São Paulo: Perspectiva, 2012.

PELED, Y. Ready made: inclusão ruidosa. In: ENCONTRO NACIONAL DA ASSOCIAÇÃO NACIONAL DE PESQUISADORES DE ARTES PLÁSTICAS DINÂMICAS EPISTEMOLÓGICAS EM ARTES VISUAIS, 16., set. 2007, Florianópolis. Anais do Encontro Nacional da ANPAP. Santa Maria: ANPAP, 2007. p. 1724-1733. Disponível em: <https://goo.gl/YHmQpp>. Acesso em: 20 jul. 2016.

ROUSSEL, R. Comment j’ai écrit certains de mes livres. 1935. Disponível em: <https://goo.gl/M8VmnQ>. Acesso em: 20 jul. 2016. 
SCHAMBERG, M.; FREYTAG-LORINGHOVEN, E. God. 1917. 1 fotografia. Disponível em: <https://goo.gl/RkKB9m>. Acesso em: 20 jul. 2016.

STAFFORD, A. Making sense of Marcel Duchamp. 2008. Disponível em: <https://goo.gl/omFS6b>. Acesso em: 20 jul. 2016.

TAYLOR, S. W. Apropos of readymades. Art and Artists, London, v. 1, n. 4, p. 46-47, jul. 1966. Special Number.

THE BLIND MAN. New York, 1917, n. 2. Disponível em: <https://goo.gl/NCqda6>. Acesso em: 20 jul. 2016.

submetido em: 04 jul. 2017 | aprovado em: 04 ago. 2017 